\title{
Long-term survival after anterior approach right hepatectomy combined with inferior vena cava thrombectomy using trans- diaphragmatic intrapericardial inferior vena cava occlusion: a case report and review of the literature
}

\author{
Yaodong Zhang ${ }^{\dagger}$, Zhengshan Wu', Ke Wang, Sheng Han, Changxian Li and Xiangcheng Li*
}

\begin{abstract}
Background: Presence of inferior vena cava tumor thrombosis (IVCTT) is an unfavorable factor to prognosis for patients with hepatocellular carcinoma (HCC).

Case presentation: Herein we report a case of HCC with IVC tumor thrombosis extending from the right hepatic vein (RHV) to the IVC, but it had not infiltrated the right atrium. Anterior approach right hepatectomy combined with IVC thrombectomy using trans-diaphragmatic IVC occlusion was performed for this patient. The patient is alive with disease-free at 32 months after treatment. A literature review was also performed. This case was demonstrated with the details and concepts of surgery.
\end{abstract}

Conclusion: This case suggested that surgical resection of HCC involving the IVC, but still outside the right atrium (RA), could offer satisfactory surgical outcomes in selected patients.

Keywords: Hepatocellular carcinoma, Inferior vena cava, Tumor thrombosis

\section{Background}

Primary hepatocellular carcinoma (HCC) accounts for 90\% of primary liver cancer in China [1]. The presence of inferior vena cava tumor thrombosis (IVCTT) in patients with HCC is considered critically closely associated with poor prognosis [2-6]. The staging system issues by the Barcelona Clinic Liver Cancer (BCLC) / American Association for the Study of Liver Diseases (AASLD) recommends the palliative care for patients in whom unsatisfactory survival is predicted [7]. With the advances in surgical techniques and increases in the quality of perioperative care, surgical

\footnotetext{
* Correspondence: drxcli@njmu.edu.cn

†Yaodong Zhang and Zhengshan Wu contributed equally to this work. Hepatobiliary Center, The First Affiliated Hospital of Nanjing Medical University; Key Laboratory of Liver Transplantation, Chinese Academy of Medical Sciences; NHC Key Laboratory of Living Donor Liver Transplantation, Nanjing, China
}

resection is associated with acceptable prognosis in HCC patients with IVCTT, especially patients who undergo R0 resection [8-10].

Herein, we report an HCC patient with IVCTT who underwent hepatectomy combined with IVC thrombectomy via the anterior approach and we summarized the treatments and outcomes of previous published studies that covered similar patients.

\section{Case presentation}

A 49-year-old male Chinese HCC patient with chronic hepatitis B virus (HBV) infection (having lasted more than 20 years) and cirrhosis. The laboratory results showed the following: alanine aminotransferase (ALT) 43.4 $\mathrm{U} / \mathrm{L}$, aspartate aminotransferase (AST) $35.7 \mathrm{U} / \mathrm{L}$, alkaline phosphatase (ALP) 200.5 U/L, gamma-glutamyl transpeptidase (GGT) $188.1 \mathrm{U} / \mathrm{L}$, bilirubin (TBil) $15.5 \mu \mathrm{mol} / \mathrm{L}$, and 
a-fetoprotein $(\mathrm{AFP})>2000 \mu \mathrm{g} / \mathrm{L}$. Liver function of the patient was Child-Pugh A grade and preoperative indocyanine green retention rate (ICG) was $10.5 \%$.

Computed tomography (CT) showed a large mass about $11.3 \times 9.9 \mathrm{~cm}^{2}$ in size in the right hepatic lobe, and a tumor thrombus (TT) in the right hepatic vein (RHV) extending into the IVC (Fig. 1a and b).

Using both his medical history and imaging findings, he was diagnosed with HCC associated with IVCTT. The clinical stage was BCLC stage C. The patient had no symptoms of right heart failure or pulmonary embolization at admission. Considering that the patient had normal hepatic function without distant metastasis, anterior approach right hepatectomy combined with IVC thrombectomy using trans-diaphragmatic intrapericardial IVC occlusion was planned for this patient (Fig. 1c).

Surgery was performed via a subcostal inverse-Lshaped incision. At laparotomy, a tumor located in the right lobe of cirrhotic liver and no detectable ascites or peritoneal metastasis was observed. After the right hepatic artery and the right portal vein branch were ligated, hepatic parenchymal resection was performed using the clamp-crushing technique with inflow occlusion (Pringle's maneuver) following the demarcation (Fig. 2a). Then the suprarenal IVC and portal vein were dissected and taped from the caudate lobe (Fig. 2b). The retrohepatic IVC below the confluence of the common channel of the left and middle hepatic veins was encircled by a vascular clamp. The diaphragm was transected via a vertical incision exposing the right atrial appendage. Then intraoperative ultrasonography was used to show that a TT in the RHV, involving the IVC, but it had not entered in the right atrium. The supradiaphragmatic IVC was encircled though trans-diaphragmatic intrapericardial IVC (Fig. 2c). The sequence of total hepatic vascular exclusion is shown in Fig. $2 \mathrm{~d}$ and the IVTT was then removed en bloc successfully with Babcock forceps, the whole removal of IVCTT with IVC exclusion cost $20 \mathrm{~min}$. The total operation required $481 \mathrm{~min}$ and the intraoperative hemorrhage was $900 \mathrm{ml}$.

The macroscopic findings of tumor measured $10 \times 11 \times$ $13 \mathrm{~cm}^{3}$ and the TT measured $3.0 \times 2.0 \mathrm{~cm} 2$ (Fig. 3a). Postoperative histological diagnosis showed moderately differentiated HCC (grade II-III Edmondson) had invaded the right hepatic vein with hepatic fibrosis and intravascular tumor thrombus. No positive resection margins or local lymph node metastasis were observed microscopically (Fig. 3b). The TNM stage was T3bNOM0.

Postoperative recovery was uneventful. The patient was discharged with few adverse events after the operation. The patient was disease-free at 32 months after the initial treatment (Fig. 3c).
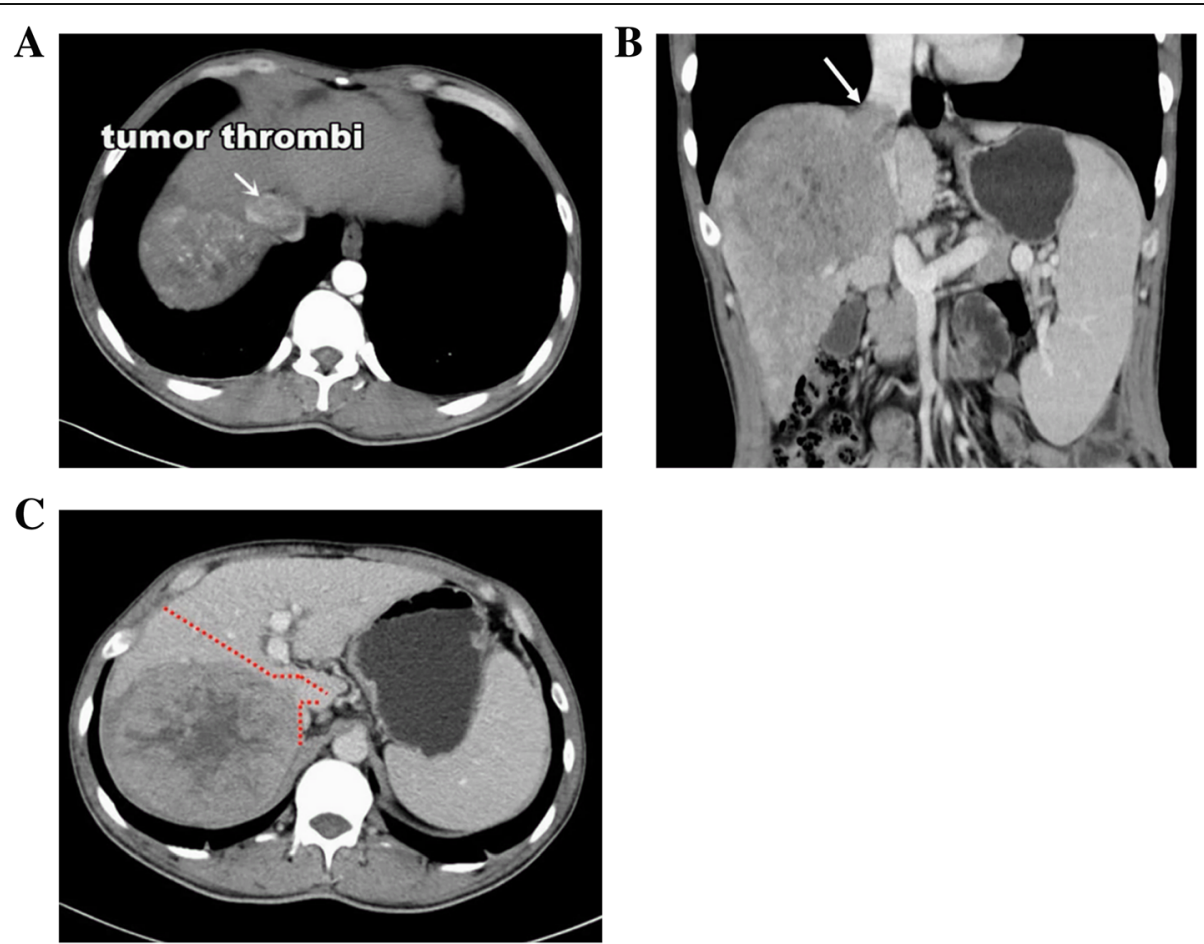

Fig. 1 a CT scan showing a huge HCC located in the right hepatic lobe with tumor thrombus (arrow) entering the IVC. b Coronal CT suggests IVTT had passed the diaphragm level, but had not enter the right atrium (arrow). c Anterior approach right hepatectomy combined with IVCTT thrombectomy 
A

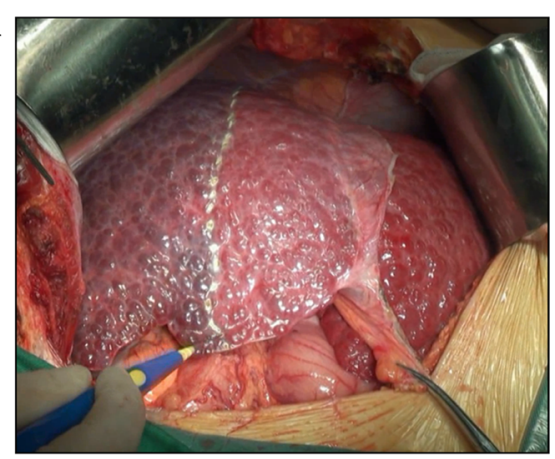

C

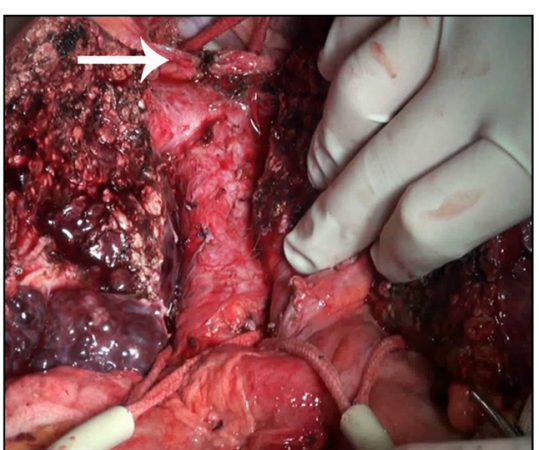

B

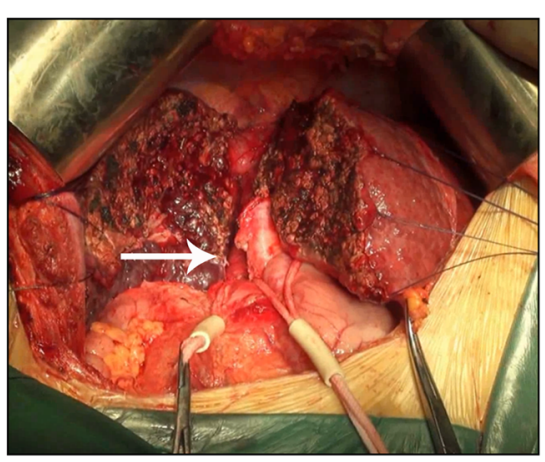

D

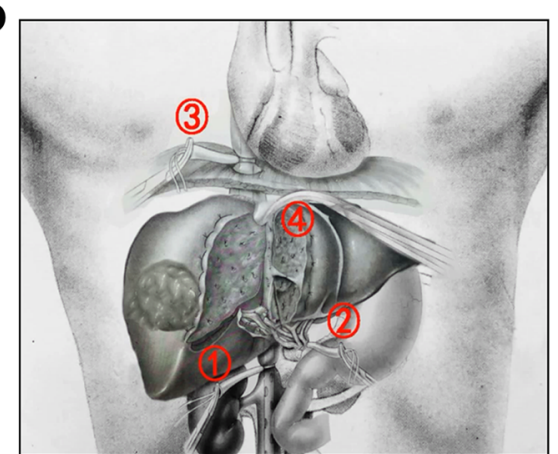

Fig. 2 a Ligation of the right hepatic artery and portal vein. b The suprarenal IVC and portal vein were dissected and encircled (arrow). c The supradiaphragmatic IVC was encircled through a vertical incision of the diaphragm (arrow). d The sequence of total hepatic vascular exclusion: (1) Suprarenal IVC (2) The portal vein (3) Supradiaphragmatic IVC (4) Retrohepatic IVC

\section{Discussion and conclusions}

Despite advances in perioperative therapy and multidisciplinary therapy, IVCTT-presenting HCC is still a significant factor for a dismal prognosis of HCC patients $[3,11,12]$. The median survival time after surgical resection for HCC with IVCTT was significantly better than that without surgical resection or in patients treated with sorafenib (47.4 vs 4/10.7 months) [3, 7]. Regarding prognosis, we reviewed 33 case reports of HCC with IVCTT (Table 1) and found the mean patient age to be $55.8 \pm$ 15.4 years, and the mean time that elapsed between diagnosis and treatment was $20 \pm 22.8$ months in the $17 \mathrm{pa}$ tients who underwent liver resection and TT, the mean time that elapsed between diagnosis and treatment was $9 \pm 4.5$ months in the 7 patients who underwent resection of TT alone, and the mean time that elapsed between diagnosis and treatment was $10.4 \pm 12.3$ months in the 12 patients who received other oncology therapy. These data indicated that aggressive radical resection of thrombus combined with hepatectomy or tumor thrombus extraction alone, might yield better survival than other non-surgical treatment.

A previous clinical study defined the subtypes of IVCTT-presenting HCC into three types based on the anatomic locations of the IVCTT and heart. The TT located within the subdiaphragmatic IVC was defined as the inferior hepatic type (Type I) (Fig. 4a), and the IVCTT extended above the diaphragm, but it had not infiltrated the RA. It was defined as superior hepatic type (Type II) (Fig. 4b), for the intracardiac type (Type III). The TT extended over the diaphragm and had entered the RA (Fig. 4c) [12].

With the advances in surgical techniques, increasing numbers of successful simultaneous resection of HCC with IVC tumor thrombosis have been reported [39]. Kokudo et al. reported that the 1-year and 3-year survival rates were 81 and $32 \%$, respectively, and the median survival time was 16.7 months [8]. Wang et al. reported that the 1-year, 3-year, and 5-year survival rates were $68,22.5$, and $13.5 \%$ and the median survival time was 19 months [10]. These data indicated that resection of HCC and IVCTT might result in better survival than other non-surgical therapies.

Cardiopulmonary bypasses $(\mathrm{CPB})$ and total hepatic vascular exclusion (THVE) have been reported in most previous resection cases [40-43]. However, these technologies have reportedly been associated with the risk of massive hemorrhage and severe vascular injury. Although other new technologies, such as venous bypass, total circulatory arrest with exsanguinations, and concomitant hypothermia, can reduce these risks, technical complexity is still the main limitation of these procedures [42, 44]. The basis 
A

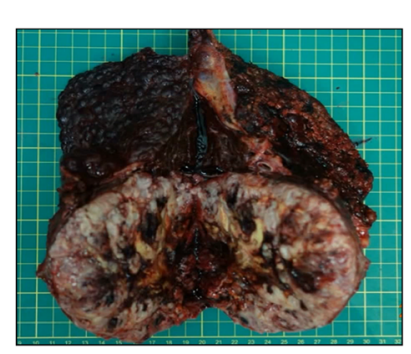

B

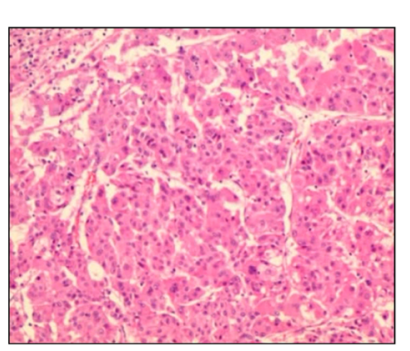

C

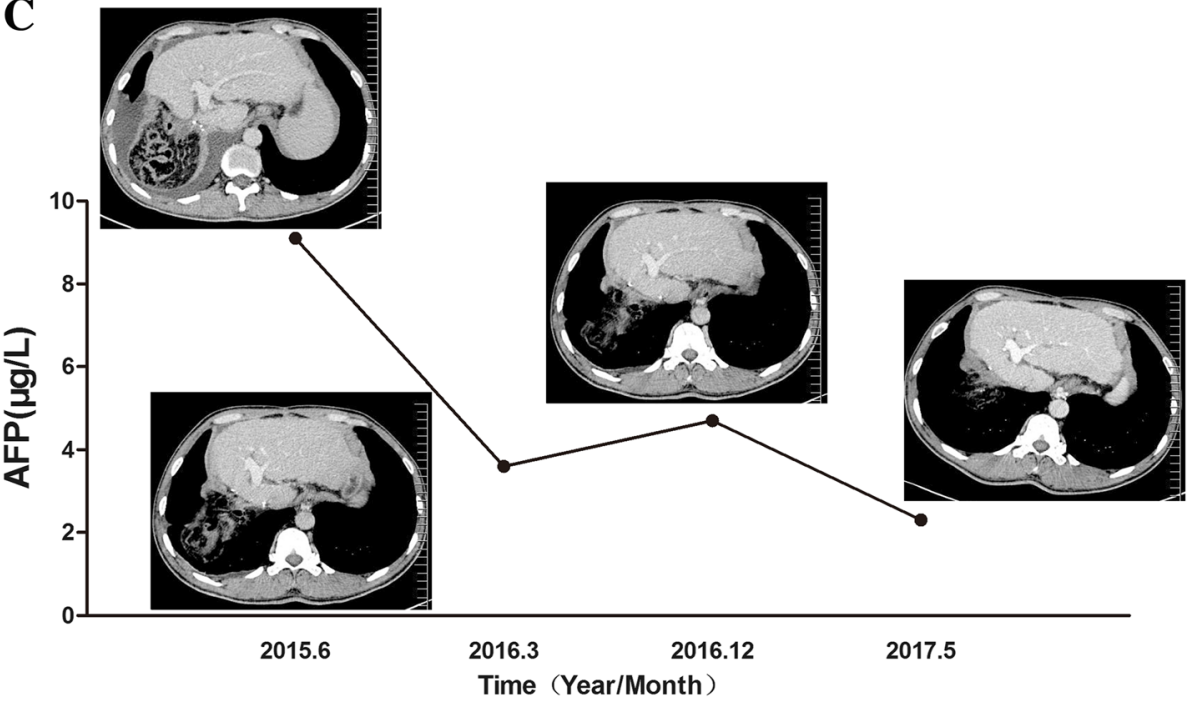

Fig. 3 a The resected tumor specimens. b Hepatocellular carcinoma, II-III, giant size, size $10 \times 11 \times 13 \mathrm{~cm}$, visible intravascular tumor thrombus, incision without tumor residual (HE staining, $\times 400$ ). c CT examinations and laboratory results of AFP showed no signs of recurrence or metastasis 32 months after the surgery

of our technique is that the IVCTT undergo no or minimal adhesion to the venous wall on any macroscopic scale. Similar ideas have been mentioned in two previous articles. We have simplified the surgery procedure and difficulty based on the new surgical concepts. It has been suggested that this surgical procedure could be suitable for HCC patients with IVCTT extended above the diaphragm without entering the RA, and it could reduce the risk of bleeding and vascular injury to a considerable intent.

No-touch surgery is difficult to perform given the anatomical characteristics of the liver [45]. Recent studies have confirmed that tumor cells diffuse more easily through the portal vein or hepatic vein during the conventional hepatectomy than through other veins and resulting in early recurrence $[46,47]$. Recently, some studies have reported that anterior approach hepatectomy, because involves less manipulation of the liver, can reduce the rate of recurrence of postoperative liver cancer, and extend patient survival [48]. Clinical, randomized controlled studies reported that halfhepatectomy in the anterior approach significantly reduced the risk of blood loss, improved the survival rate, ensured surgical vision, and reduced the perioperative mortality rate [49].

During this procedure, a process termed the peelingoff technique was performed because tumor thromboses do not adhere to the wall of the IVC. Previous studies have proved that the peeling off technique can improve the surgical outcome of $\mathrm{HCC}$ with portal vein tumor thrombus [50, 51]. We reported the resection for HCC with IVCTT using the peeling off technique and the long-term survival outcomes are comparable to the current case reports. The low incidence of IVC tumor thrombus in HCC should not preclude the development of new surgical approaches because the peeling-off technique is a minimally invasive approach and deserves further investigation.

In this case, because the IVCTT is above the diaphragm but still outside the RA, the intrathoracic IVC is approached by an abdominal incision of the diaphragm, without the need for a median sternotomy or thoracotomy $[52,53]$. This method prevents any need for splitting the sternum and also reduced surgical trauma, keeping the IVC hiatus and preserved the normal anatomical structures, and offered good surgical exposure. 


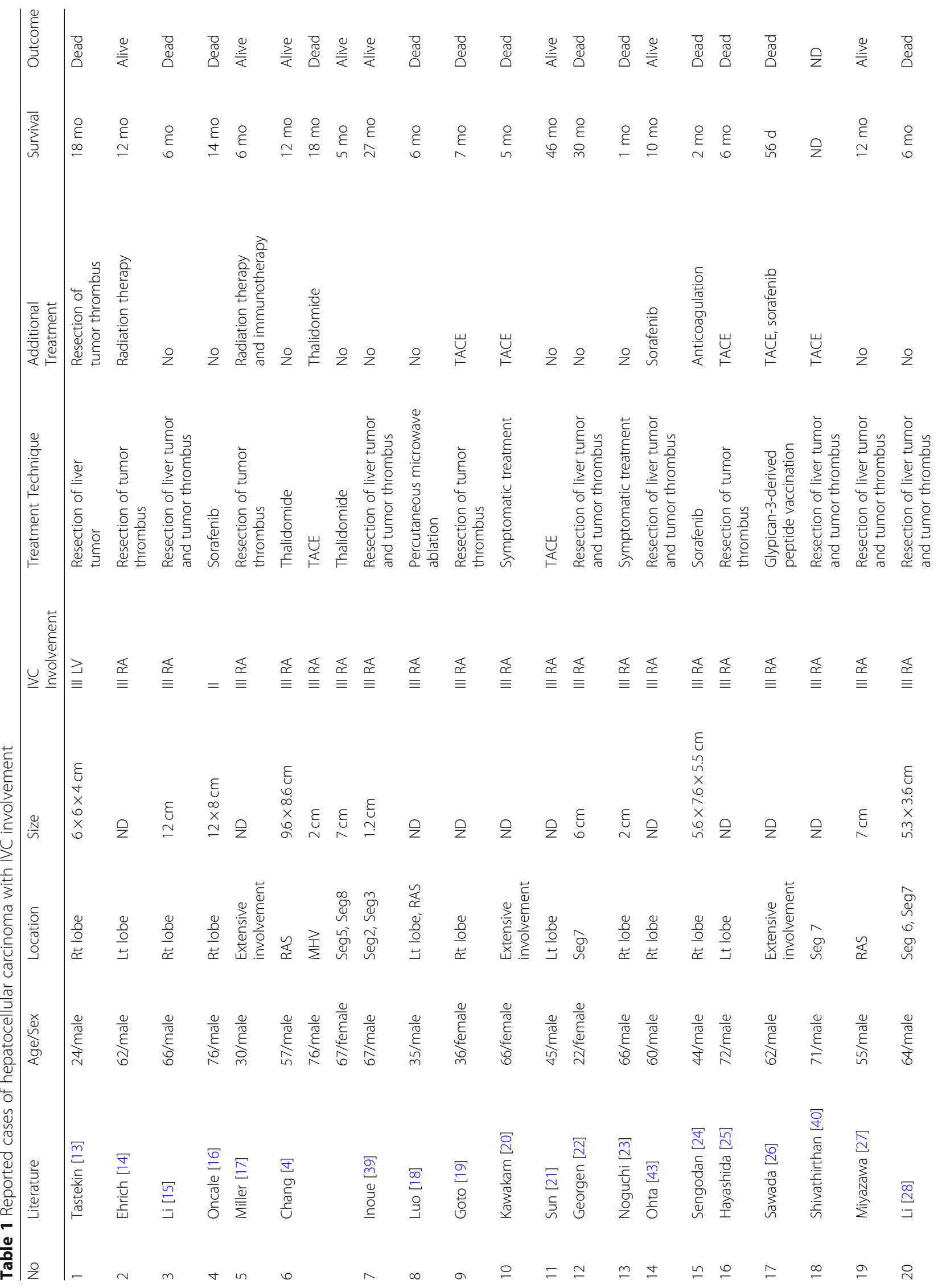




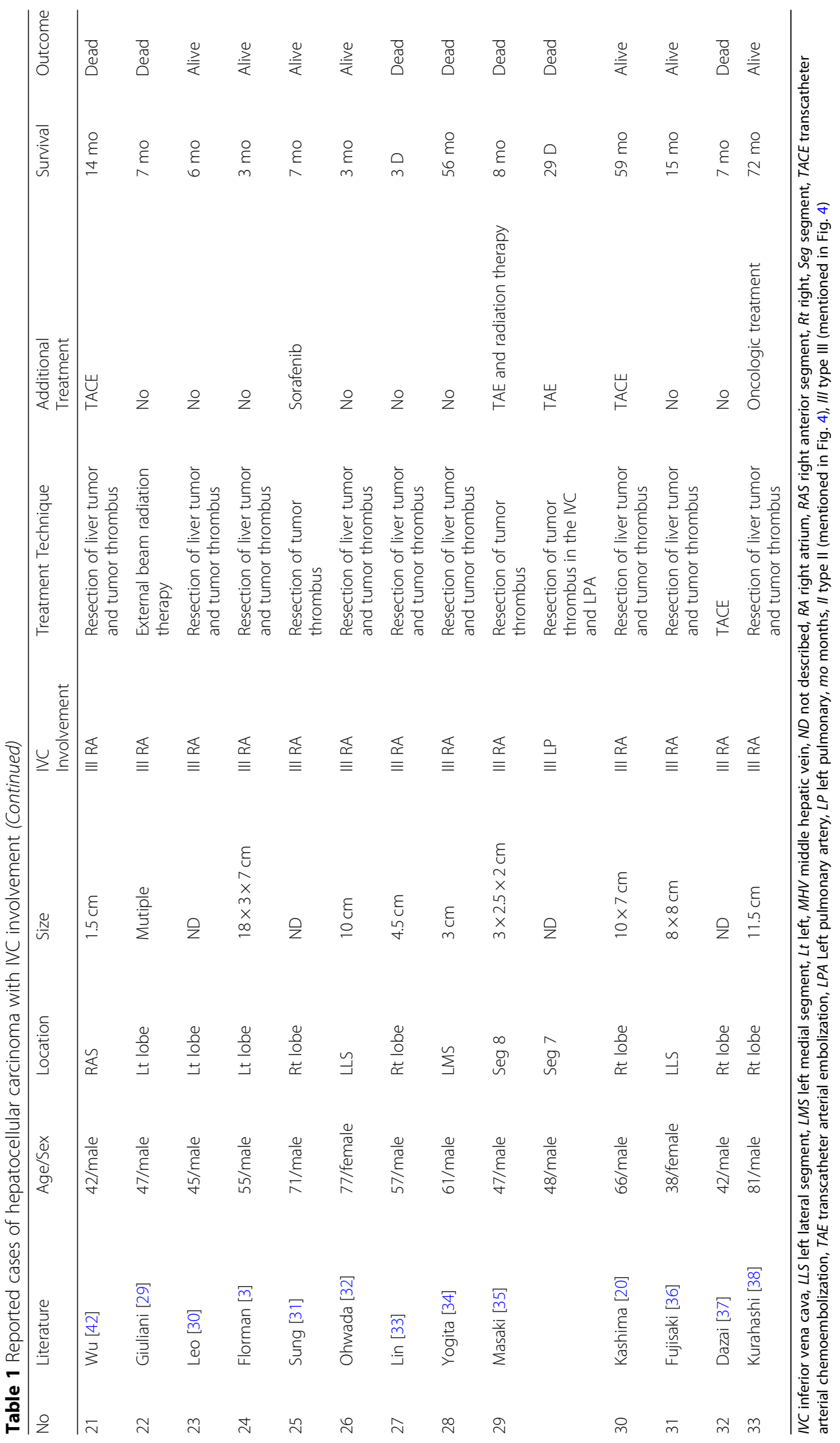




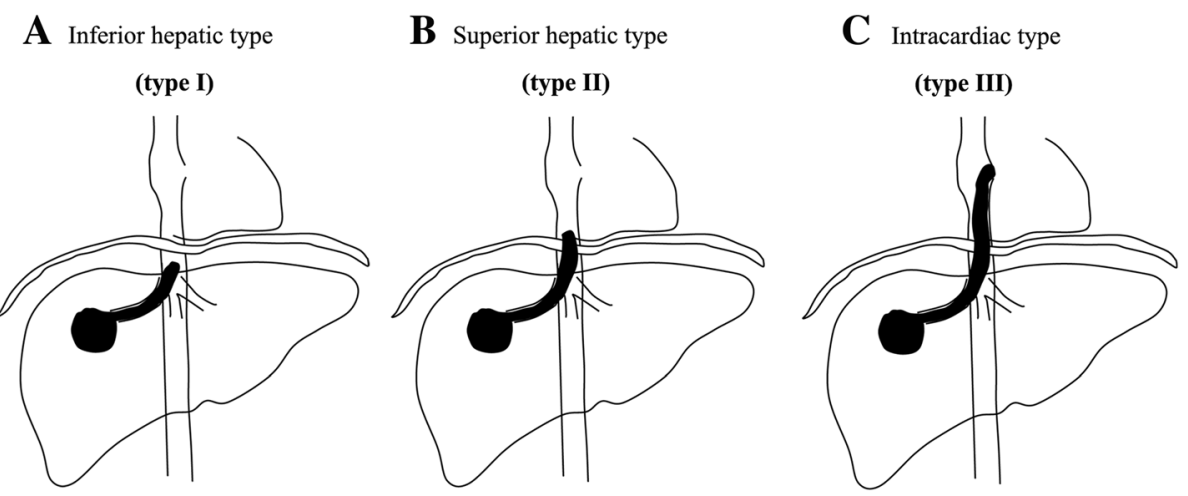

Fig. 4 IVCTT-presenting HCC is classified into three types. a The TT located within the subdiaphragmatic IVC; b The IVCTT extended above the diaphragm, but it had not infiltrated the RA; and (c) The TT extended over the diaphragm and had advanced into the RA

In conclusion, radical resection of both $\mathrm{HCC}$ and IVCTT could be a practical surgical option and useful therapeutic modality for achieving long-term survival or HCC patients with IVCTT extending to the IVC, especially for those IVCTT extending over the diaphragm but outside the RA.

\section{Abbreviations}

CT: Computed tomography; HBV: Hepatitis B virus; HCC: Hepatocellular carcinoma; IVC: Inferior vena cava; TACE: Transcatheter arterial chemoembolization; TAE: Transcatheter arterial embolization; TT: Tumor thrombosis

\section{Authors' contributions}

YDZ: collected all references and wrote the draft. KW: responsible for providing the information of surgery. CXL and SH: collected all data of the clinical. ZSW and XCL: offered the conception and design, revised and discussed the meaning of the manuscript. All authors read and approved the final manuscript.

\section{Funding}

Supported by National Science Foundation of China (NO.81670570)

\section{Availability of data and materials}

All data generated or analyzed during this study are included in this published article.

\section{Ethics approval and consent to participate}

Written informed consent was obtained from the patient for publication of this case report and accompanying images. The ethics committee of the First Affiliated Hospital of Nanjing medical University has approved this study.

\section{Consent for publication}

Written informed consent was obtained from the patient for publication of this case report and accompanying images. A copy of the written consent is available for review by the Editor of this journal.

\section{Competing interests}

The authors declare that they have no competing interests.

Received: 28 February 2018 Accepted: 29 July 2019

Published online: 28 August 2019

\section{References}

1. El-Serag HB, Rudolph KL. Hepatocellular carcinoma: epidemiology and molecular carcinogenesis. Gastroenterology. 2007;132(7):2557-76.
2. Lee IJ, Chung JW, Kim HC, et al. Extrahepatic collateral artery supply to the tumor thrombi of hepatocellular carcinoma invading inferior vena cava: the prevalence and determinant factors. J Vasc Interv Radiol. 2009;20(1):22-9.

3. Florman $\mathrm{S}$, Weaver M, Primeaux $\mathrm{P}$, et al. Aggressive resection of hepatocellular carcinoma with right atrial involvement. Am Surg. 2009; 75(11):1104-8.

4. Chang JY, Ka WS, Chao TY, et al. Hepatocellular carcinoma with intra-atrial tumor thrombi. A report of three cases responsive to thalidomide treatment and literature review. Oncology. 2004;67(3-4):320-6.

5. Koo JE, Kim JH, Lim YS, et al. Combination of transarterial chemoembolization and three-dimensional conformal radiotherapy for hepatocellular carcinoma with inferior vena cava tumor thrombus. Int J Radiat Oncol Biol Phys. 2010;78(1):180-7.

6. Cuevas $\mathrm{C}$, Raske $\mathrm{M}$, Bush $\mathrm{WH}$, et al. Imaging primary and secondary tumor thrombus of the inferior vena cava: multi-detector computed tomography and magnetic resonance imaging. Curr Probl Diagn Radiol. 2006;35(3):90-101.

7. Llovet JM, Ricci S, Mazzaferro V, et al. Sorafenib in advanced hepatocellular carcinoma. N Engl J Med. 2008;359(4):378-90.

8. Kokudo T, Hasegawa K, Yamamoto S, et al. Surgical treatment of hepatocellular carcinoma associated with hepatic vein tumor thrombosis. J Hepatol. 2014;61(3):583-8.

9. Wakayama K, Kamiyama T, Yokoo H, et al. Surgical management of hepatocellular carcinoma with tumor thrombi in the inferior vena cava or right atrium. World J Surg Oncol. 2013;11:259.

10. Wang $Y$, Yuan $L$, Ge RL, et al. Survival benefit of surgical treatment for hepatocellular carcinoma with inferior vena cava/right atrium tumor thrombus: results of a retrospective cohort study. Ann Surg Oncol. 2013; 20(3):914-22.

11. Pawlik TM, Poon RT, Abdalla EK, et al. Hepatectomy for hepatocellular carcinoma with major portal or hepatic vein invasion: results of a multicenter study. Surgery. 2005;137(4):403-10.

12. Truty MJ, Vauthey JN. Surgical resection of high-risk hepatocellular carcinoma: patient selection, preoperative considerations, and operative technique. Ann Surg Oncol. 2010;17(5):1219-25.

13. Tastekin $\mathrm{E}$, Usta U, Ege $\mathrm{T}$, et al. Cardiac metastasis of hepatocellular carcinoma in a young non-cirrhotic patient, to the left ventricle. Ann Hepatol. 2012;11(3):392-4.

14. Ehrich DA, Widmann JJ, Berger RL, et al. Intracavitary cardiac extension of hepatoma. Ann Thorac Surg. 1975;19(2):206-11.

15. Li AJ, Yuan $H$, Yin L, et al. Cavoatrial thrombectomy in hepatocellular carcinoma with tumor thrombus in the vena cava and atrium without the use of cardiopulmonary bypass. Ann Vasc Surg. 2014;28(6):1565 e1565-8.

16. Oncale M, Lewis B. Hepatocellular carcinoma with extension to the heart via the inferior vena cava. Proc (Bayl Univ Med Cent). 2015;28(2):229-30.

17. Miller DL, Katz NM, Pallas RS. Hepatoma presenting as a right atrial mass. Am Heart J. 1987;114(4 Pt 1):906-8.

18. Luo $X$, Zhang B, Dong $S$, et al. Hepatocellular carcinoma with tumor Thrombus occupying the right atrium and portal vein: a case report and literature review. Medicine (Baltimore). 2015;94(34):e1049. 
19. Goto H, Kaneko Y, Utoh J, et al. Surgery of hepatoma with intracavitary cardiac extension. Heart Vessel. 1986;2(1):60-2.

20. Kashima $Y$, Miyazaki $M$, Ito $H$, et al. Effective hepatic artery chemoembolization for advanced hepatocellular carcinoma with extensive tumour thrombus through the hepatic vein. J Gastroenterol Hepatol. 1999; 14(9):922-7

21. Sun $\mathrm{JH}$, Zhang $\mathrm{YL}$, Nie $\mathrm{CH}$, et al. Long-term survival after chemoembolization of metastatic right atrial tumor thrombus as a presenting feature of hepatocellular carcinoma: a case study. Oncol Lett. 2012;3(5):975-7.

22. Georgen M, Regimbeau JM, Kianmanesh $R$, et al. Removal of hepatocellular carcinoma extending in the right atrium without extracorporal bypass. J Am Coll Surg. 2002;195(6):892-4.

23. Noguchi H, Hirai K, Itano S, et al. Small hepatocellular carcinoma with intravascular tumor growth into the right atrium. J Gastroenterol. 1994; 29(1):41-6.

24. Sengodan P, Grewal H, Gandhi S. Invasive hepatocellular carcinoma with recurrent pulmonary embolism: use of AngioVac cannula thrombectomy device for mechanical aspiration. J Invasive Cardiol. 2014;26(7):E100-3.

25. Hayashida K, Okumura S, Kawase T. Right atrial obstruction due to cardiac extension of hepatocellular carcinoma. Asian Cardiovasc Thorac Ann. 2014; 22(4):465-8

26. Sawada Y, Yoshikawa T, Fujii S, et al. Remarkable tumor lysis in a hepatocellular carcinoma patient immediately following glypican-3derived peptide vaccination: an autopsy case. Hum Vaccin Immunother. 2013;9(6):1228-33

27. Miyazawa M, Torii T, Asano H, et al. Does a surgery for hepatocellular carcinoma with tumor thrombus highly occupying in the right atrium have significance? A case report and review of the literature. Hepatogastroenterology. 2005;52(61):212-6.

28. Li SS, Jian LL, Gang PB, et al. Removal of hepatocellular carcinoma extending into the right atrium with extracorporeal circulation. Hepatogastroenterology. 2012;59(117):1591-3.

29. Giuliani ME, Knox J, Dawson LA. Malignant intracardiac thrombus from hepatocellular carcinoma treated with external beam radiation therapy. J Palliat Med. 2010;13(10):1293-5.

30. Leo F, Rapisarda F, Stefano PL, et al. Cavo-atrial thrombectomy combined with left hemi-hepatectomy for vascular invasion from hepatocellular carcinoma on diseased liver under hypothermic cardio-circulatory arrest. Interact Cardiovasc Thorac Surg. 2010;10(3):473-5.

31. Sung AD, Cheng S, Moslehi J, et al. Hepatocellular carcinoma with intracavitary cardiac involvement: a case report and review of the literature. Am J Cardiol. 2008;102(5):643-5.

32. Ohwada S, Takahashi T, Tsutsumi H, et al. Hepatocellular carcinoma with a tumour thrombus extending to the tricuspid valve: report of a successful en bloc resection. Hepatogastroenterology. 2008;55(84):903-6.

33. Lin $\mathrm{HH}$, Hsieh $\mathrm{CB}, \mathrm{Chu} \mathrm{HC}$, et al. Acute pulmonary embolism as the first manifestation of hepatocellular carcinoma complicated with tumor thrombi in the inferior vena cava: surgery or not? Dig Dis Sci. 2007;52(6):1554-7.

34. Yogita S, Tashiro S, Harada M, et al. Hepatocellular carcinoma with extension into the right atrium: report of a successful liver resection by hepatic vascular exclusion using cardiopulmonary bypass. J Med Investig. 2000;47(3-4):155-60.

35. Masaki N, Hayashi S, Maruyama T, et al. Marked clinical improvement in patients with hepatocellular carcinoma by surgical removal of extended tumor mass in right atrium and pulmonary arteries. Cancer Chemother Pharmacol. 1994;33(Suppl):S7-11.

36. Fujisaki M, Kurihara E, Kikuchi K, et al. Hepatocellular carcinoma with tumor thrombus extending into the right atrium: report of a successful resection with the use of cardiopulmonary bypass. Surgery. 1991;109(2):214-9.

37. Dazai $Y$, Katoh T, Katoh I, et al. Effectiveness of chemoembolization therapy for metastatic right atrial tumor thrombus associated with hepatocellular carcinoma. Chest. 1989;96(2):434-6

38. Kurahashi S, Sano T, Natsume S, et al. Surgical treatment after hepatic arterial infusion chemotherapy for hepatocellular carcinoma extending into the right atrium. Surg Case Rep. 2015;1(1):47.

39. Inoue $Y$, Hayashi M, Katsumata $T$, et al. Hepatocellular carcinoma with right atrial tumor thrombus: report of a case. Surg Today. 2011;41(8):1122-9.

40. Shivathirthan N, Shimoda M, Kosuge T, et al. Recurrent hepatocellular carcinoma with tumor thrombus in right atrium - report of a successful liver resection with tumor thrombectomy using total hepatic vascular exclusion without concomitant cardiopulmonary bypass. Hepatogastroenterology. 2012;59(115):872-4

41. Kawamoto K, Eguchi $H$, Wada $H$, et al. A case of successful surgical resection followed by S-1 administration for hepatocellular carcinoma with lung metastases and a tumor thrombus into right atrium. Gan To Kagaku Ryoho. 2011;38(12):2490-2

42. Wu CC, Hseih S, Ho WM, et al. Surgical treatment for recurrent hepatocellular carcinoma with tumor thrombi in right atrium: using cardiopulmonary bypass and deep hypothermic circulatory arrest. J Surg Oncol. 2000;74(3):227-31.

43. Ohta M, Nakanishi C, Kawagishi N, et al. Surgical resection of recurrent extrahepatic hepatocellular carcinoma with tumor thrombus extending into the right atrium under cardiopulmonary bypass: a case report and review of the literature. Surg Case Rep. 2016;2(1):110.

44. Azoulay $D$, Andreani $P$, Maggi $U$, et al. Combined liver resection and reconstruction of the supra-renal vena cava: the Paul Brousse experience. Ann Surg. 2006:244(1):80-8.

45. Pawlik TM, Delman KA, Vauthey JN, et al. Tumor size predicts vascular invasion and histologic grade: implications for selection of surgical treatment for hepatocellular carcinoma. Liver Transpl. 2005;11(9):1086-92.

46. Yamanaka N, Okamoto E, Fujihara S, et al. Do the tumor cells of hepatocellular carcinomas dislodge into the portal venous stream during hepatic resection? Cancer. 1992;70(9):2263-7.

47. Matsumata T, Kanematsu T, Takenaka K, et al. Lack of intrahepatic recurrence of hepatocellular carcinoma by temporary portal venous embolization with starch microspheres. Surgery. 1989;105(2 Pt 1):188-91.

48. Li L, Wang HQ, Wang Q, et al. Anterior vs conventional approach hepatectomy for large liver cancer: a meta-analysis. World J Gastroenterol. 2014;20(45):17235-43.

49. Liu CL, Fan ST, Cheung ST, et al. Anterior approach versus conventional approach right hepatic resection for large hepatocellular carcinoma: a prospective randomized controlled study. Ann Surg. 2006;244(2):194-203.

50. Inoue $Y$, Hasegawa $K$, Ishizawa $T$, et al. Is there any difference in survival according to the portal tumor thrombectomy method in patients with hepatocellular carcinoma? Surgery. 2009;145(1):9-19.

51. Yamamoto S, Hasegawa K, Inoue $Y$, et al. Bile duct preserving surgery for hepatocellular carcinoma with bile duct tumor thrombus. Ann Surg. 2015; 261(5):e123-5.

52. Miyazaki M, Ito $\mathrm{H}$, Nakagawa $\mathrm{K}$, et al. An approach to intrapericardial inferior vena cava through the abdominal cavity, without median sternotomy, for total hepatic vascular exclusion. Hepatogastroenterology. 2001;48(41):1443-6.

53. Chen TW, Tsai CH, Chou SJ, et al. Intrapericardial isolation of the inferior vena cava through a transdiaphragmatic pericardial window for tumor resection without sternotomy or thoracotomy. Eur J Surg Oncol. 2007;33(2):239-42.

\section{Publisher's Note}

Springer Nature remains neutral with regard to jurisdictional claims in published maps and institutional affiliations.

Ready to submit your research? Choose BMC and benefit from:

- fast, convenient online submission

- thorough peer review by experienced researchers in your field

- rapid publication on acceptance

- support for research data, including large and complex data types

- gold Open Access which fosters wider collaboration and increased citations

- maximum visibility for your research: over $100 \mathrm{M}$ website views per year

At $\mathrm{BMC}$, research is always in progress.

Learn more biomedcentral.com/submission 